\title{
Recombinant Cell-Surface Anchored Sialidase DAS181
}

National Cancer Institute

\section{Source}

National Cancer Institute. Recombinant Cell-Surface Anchored Sialidase DAS181. NCI

Thesaurus. Code C113163.

A recombinant sialidase fusion protein composed of a sialidase catalytic domain derived from Actinomyces viscosus, a constituent of the normal oral and gastrointestinal flora in humans, fused to a cell surface-anchoring domain, with potential anti-viral activity. Following administration by oral inhalation, DAS181 proteolytically removes sialic acid from the airway epithelium, which inhibits viral binding to and internalization by cells of the respiratory epithelium and prevents viral replication. The cell surface anchoring-domain of this agent may increase retention time and drug potency. Sialic acids in the respiratory tract are used by influenza and parainfluenza viruses to invade airway epithelial cells. 